\title{
Herbal extraction procedures: need of the hour
}

\section{Nandhini Saravanabavan, Kartik J. Salwe*, R. Sudar Codi, Manimekalai Kumarappan}

Department of Pharmacology, Mahatma Gandhi Medical College and Research Institute, SBV, Puducherry, India

Received: 15 May 2020

Accepted: 09 June 2020

*Correspondence:

Dr. Kartik J. Salwe,

Email:kartiksalwe@gmail.com

Copyright: ( $)$ the author(s), publisher and licensee Medip Academy. This is an open-access article distributed under the terms of the Creative Commons Attribution Non-Commercial License, which permits unrestricted non-commercial use, distribution, and reproduction in any medium, provided the original work is properly cited.

\begin{abstract}
Extraction is the first most important step for preparing herbal drug formulations. It serves as an alternate method to identify the lead compound by isolating the active compounds from the crude drug using various extraction techniques by adding suitable solvent. Selection of solvent is the most important step as the success rate depends on it. Thus, by identifying the lead compound, extraction plays an important role in the process of drug discovery. In this review, different methods of extraction used for extracting the herbal extracts have been discussed with their advantages and disadvantages and also a brief discussion on solvent selection and actions of few phytochemicals have also been discussed.
\end{abstract}

Keywords: Herbal extraction, Soxhlation, Percolation, Percolation, Sonication

\section{INTRODUCTION}

From ancient times, mankind uses plant source to cure illness. Though many allopathic medicines are available but with significant side effects. Thus, the active compounds of plant byproducts act as cheap and effective source of medicines. ${ }^{1}$ The various parts of the plant like leaves, seeds, fruits contain active compounds like tannins, flavonoids, saponins which have medicinal properties. Hence the beneficial effects of plants are derived from these active compounds. In order to isolate these active compounds, the extracts of various plant parts have to be prepared. Thus, while preparing plant formulations extraction of active components acts as the first important step. It is the preliminary step in herbal drug preparation and it brings plant metabolites into solvents. Extraction is defined as the process by which desired or active constituents are withdrawn from crude drug using selected solvents in which desired constituents are soluble. The main aim of doing this extraction is to obtain therapeutically desired component and also to avoid inactive components using selected solvent called menstruum. There are conventional and also nonconventional technique of isolation. ${ }^{2}$ Appropriate method of extraction technique is selected for better extraction efficiency. ${ }^{3}$

\section{MACERATION}

It is the simple and commonly used procedure in research on herbal extract. The drug is introduced into the bottle with menstruum or the solvent and tightly stoppered and agitated occasionally for 3-7 days. The liquid should be poured off and the residue should be expressed and filter the mixed liquids. ${ }^{4}$ The drugs are macerated in definite quantities of menstruum at a temperature range from 15$20^{\circ}$ C. It mainly acts by releasing phytochemicals or chemical compound of interest by destructing the cell wall. $^{5}$ Due to difficulty of extracting completely the active constituents with one maceration, the process is repeated with same or different solvents or with different quantities of solvent. Such process is termed as double maceration/triple maceration. ${ }^{6}$ It is used in extraction of some drugs, notably those containing little/no cellular structure such as benzoin. The advantages of this process are that no particular skills are required to do maceration technique and soaking process is also completed in short 
period of time. But the longer duration of extraction and lower efficacy limits its use.

\section{PERCOLATION}

It is a continuous process in which the saturated solvent is constantly being replaced by fresh solvent making it more effective procedure than maceration. ${ }^{7}$ The most suitable method for soil extraction is hot water percolation and for oil extraction is cold percolation. ${ }^{8,9}$ It is used mostly to extract active ingredients using percolator (a narrow cone shape vessel open at both ends). Initial step in percolation is that the powder should be moistened with appropriate amount of solvent in a well closed container for approximately for 4 hours and then the mass is placed into the percolator and top of the percolator is closed. Then the solvent is further added on the top to form a shallow layer and this mixture should be macerated in closed percolator for 24 hours. Outlet of percolator which is present at the bottom is then opened and liquid which is present is drained through it slowly. This process is usually done at moderate rate (6 drops/min). Additional solvent can be added to percolator as required and the liquid is clarified by filtration or by standing followed by decanting. ${ }^{10}$

\section{Table 1: Difference between maceration and percolation procedures}

\begin{tabular}{|ll|}
\hline Maceration & Percolation \\
\hline $\begin{array}{l}\text { A process of becoming } \\
\text { softened by soaking in a } \\
\text { liquid }\end{array}$ & $\begin{array}{l}\text { A process of liquid } \\
\text { slowly passing through } \\
\text { a filter }\end{array}$ \\
\hline $\begin{array}{l}\text { Main purpose is to obtain } \\
\text { softer substances in a liquid } \\
\text { medium }\end{array}$ & $\begin{array}{l}\text { Main purpose is to } \\
\text { extract particular } \\
\text { substance into liquid }\end{array}$ \\
\hline & $\begin{array}{l}\text { Results in liquid that } \\
\text { only contains desired } \\
\text { substances dissolved in } \\
\text { Results in liquid with waste } \\
\text { and has to be purified further }\end{array}$ \\
$\begin{array}{l}\text { it. Hence no further } \\
\text { purification is required }\end{array}$ \\
\hline Takes long time & Takes less time \\
\hline Do not require equipment & $\begin{array}{l}\text { Requires equipment's } \\
\text { such as filter }\end{array}$ \\
\hline
\end{tabular}

\section{INFUSION}

It is very simple method of extraction in which the fresh infusions are prepared by macerating the crude drug with cold and hot water at a room temperature for a short period of time of approximately 5-15 minutes and then filtered by using filter paper. ${ }^{11}$ The dilute solution obtained contains readily soluble components of crude drug. Preparation of tea infusion is one such example. ${ }^{12}$

\section{DECOCTION}

It is suitable for heat stable and water-soluble compounds. This is used in preparing ayurvedic extracts.
In this process the crude drug is boiled in a specific amount of water for a particular time period 15-30 minutes then it is cooled, strained and filtered starting ratio of crude drug to water is $1: 4$ or $1: 16$. The volume should be brought down to one fourth its original volume by boiling and then the concentrated extract is filtered and used further. Decoction are preferred for harder herbs (root, seed and bark). ${ }^{13}$

\section{DIGESTION}

Digestion is the form of maceration which consists of the application of gentle heat to the substance being treated. It is used in those cases where moderately elevated temperature is unobjectionable, the heat increases the power of solvent menstrum. ${ }^{14}$

\section{SOXHLATION}

It is most frequently used for isolation of organic pollutants from environmental samples for last 20 years. ${ }^{15}$ In this procedure, the water lines are hooked up to the condenser and the lines are secured with copper wire/plastic straps to avoid water spillage. The top of the condenser should not be capped and the crude drug is placed into the thimble/porous bag made up of filter paper approximately $1 \mathrm{~cm}$ space should be left between sample and top of thimble. The solvent flask should be filled with $60-70 \%$ of solvent and place it into the heating source. The extracting solvent is now heated and its vapor will be condensed in the condenser. The condensed extractant gets dripped into the thimble containing the crude drug. When the level of liquid which is present in the chamber rises to top of siphon tube, the liquid content of chamber siphon into the flask. The process continued until drop of solvent from siphon tube does not leave residue when evaporated. ${ }^{16}$ The main advantage of soxhlation is that large amount of drug can be extracted with less quantity if solvent and without impurities. It is also economical in terms of time, energy and financial inputs but the important disadvantages are that if there is any break in the water line or leakage of solvent or any glassware problems power to the heat source should be turned off immediately and water tap should also be closed. The potential hazards include that the source of heating is electric so that the exposed wires should not be touched, refluxing solvents and glass wares are hot thus it is necessary to be cautious while monitoring extraction to avoid heat burns and solvents which are used are also flammable.

\section{MICROWAVE ASSISTED EXTRACTION}

It is the popular and cost-effective extraction methods and this type of extraction has gained an additional importance. It is the combination of microwave and traditional solvent extraction. ${ }^{17}$ Microwaves are electromagnetic radiations with a frequency from 0.3-300 GHz. ${ }^{18}$ Owing to their electromagnetic nature, microwaves possess electric and magnetic fields which 
are perpendicular to each other. Electric field causes heating by 2 mechanism namely dipolar rotation and ionic conduction. ${ }^{19}$ When plant material is immersed inside a microwave transparent solvent, the heat of microwave radiation directly reaches to the solid without being absorbed by the solvent, resulting in instantaneous heating. Heating causes moisture to evaporate and breaks the cell wall of substrate and releases the content into solvent. It is soluble for polar molecules but it is not suitable for extraction of non-polar molecules. The main advantages of this procedure are that it is cheap, requires only less amount of solvent with high extraction rate and minimum consumption of time. But some disadvantages of this procedure are that it is not suitable for non-polar compounds and heat labile compounds. The efficiency is also not so good and additional filtration is required in this procedure.

\section{ULTRASOUND (SONICATION) \\ ASSISTED EXTRACTION}

It is widely used to extract active compounds because of its high extraction efficiency which can be gained at low temperature. ${ }^{20}$ This involves high intensity and high frequency sound waves ranging from $20 \mathrm{KHz}$ to 2000 $\mathrm{KHz}$ which will increase the cell wall permeability by mechanical effect and produces cavitation and thus the contact between solvent and sample will be increased. When the frequency is more than $20 \mathrm{KHz}$ the physical and chemical properties of crude material will be changed. ${ }^{21}$ Most profitable period is first few minutes during which the extraction rate is high. ${ }^{22}$ It is effective for caffeine extraction. The advantages of this extraction technique are that it requires less amount of solvent and minimum time with effective extraction and it is also useful for heat sensitive compounds as moderate temperature is required. But there are some disadvantages like the quality of the extract might be changed as there is release of free radicals and also the physical and chemical properties of crude material will be changed.

\section{SUPERCRITICAL FLUID EXTRACTION}

Supercritical fluid extraction is the process of separating one component from another using supercritical fluid as the extracting solvent. ${ }^{23}$ A fluid is said to be supercritical if its pressure and temperature are more than its critical temperature and pressure. ${ }^{24}$ In supercritical fluid extraction, $\mathrm{CO}_{2}$ is the most widely used solvent for extraction of natural products because of its safety, nontoxic, non-flammable characteristics. It is also economical and easily available. It requires temperature near ambient which makes it suitable for extraction of heat labile and non-polar compounds without degradation. $^{25}$ At critical temperature and pressure Supercritical fluid have physical properties of gas and liquid. $\mathrm{CO}_{2}$ behaves as supercritical fluid at above $31.3^{\circ}$ $\mathrm{C}$ and 72.9 atm. $^{26}$ By adding ethanol/methanol it will increase the solubility of water-soluble compounds. Efficiency depends on pressure and temperature. It is fast process and it can be employed in 10-60 minutes. The advantages of this type of extraction is that it is ecofriendly, recycling of carbon dioxide and it requires only less cost and the time required is also minimum. And mainly the $\mathrm{CO}_{2}$ is safe, inexpensive and also easily available. But the disadvantage is that the supercritical fluid can easily be removed after extraction by lowering the temperature or pressure or both.

\section{SOLVENT SELECTION}

Type of solvents used in extraction procedures determines the success rate of determination of biologically active compounds from the plant materials. There are many factors which determine the efficiency of extraction one of the important factors is selection of solvents. There are also other factors like solubility of metabolites in selected solvents, extraction temperature which also affects the efficiency of extraction.

Depending upon the molecular structure, a molecule may be water soluble or water insoluble. Water insoluble compounds are mainly extracted using organic solvents like chloroform, ethanol, methanol, acetone. The solvent which is selected for extraction should not affect the original properties of the compound to be extracted. The various solvents used in the extraction are mentioned below.

\section{Water}

It is considered as universal solvent. It is the solvent of choice from the point of economy. It is mainly used to extract plant products which contains antimicrobial activity. Though it has been used traditionally but extract prepared using organic solvents will produce more antimicrobial effect. ${ }^{27}$ The major disadvantages of using water is that it requires more meat than alcohol during evaporation, long period of heating promote hydrolysis and produces further decompensation, causes more swelling of plant tissue, solvent properties differs from time to time.

\begin{abstract}
Alcohol
It is used as solvent because of its various properties such as it has more selective action, latent heat of evaporation low, improves stability of solution, less toxic internally, less hydrolysis. $30 \%$ water is added to $70 \%$ of ethanol to improve the solvent polarity and to yield more active flavonoids. Ethanol extracts the intracellular ingredients as it easily penetrates the cell membrane. ${ }^{28}$ Methanol is highly polar compared to ethanol. But methanol is cytotoxic hence it is not suitable for extraction.
\end{abstract}

\section{Hydroalcoholic extract}

It is the most widely used solvent. Combine the effects of both water and alcohol and suitable for extraction of 
active compounds. The hydroalcoholic extract gives protection against contamination of micro-organisms.

\section{Acetone}

Many lipophilic and hydrophilic compounds can be dissolved by acetone. It is less toxic and highly volatile. It is mainly used to extract the phenolic compounds, tannins and also saponins which has antimicrobial activity. ${ }^{29}$

\section{Chloroform}

It is mostly used to extract terpenoids and flavonoids.

\section{Ether}

Coumarins and fatty acids are commonly extracted using ether.

Table 2: Action of some phytochemicals.

\begin{tabular}{|ll|}
\hline $\begin{array}{l}\text { Phytochemicals } \\
\text { Alkaloids }\end{array}$ & Actions \\
\hline $\begin{array}{l}\text { Phenolic } \\
\text { compounds }\end{array}$ & Anti-oxidant $^{31}$ \\
\hline Flavonoids & $\begin{array}{l}\text { Anti-oxidant, anti-inflammatory } \\
\text { and anti-carcinogenic }^{32}\end{array}$ \\
\hline Saponins & Anti-cancer $^{33}$ \\
\hline Tannins & Astringent $^{34}$ \\
\hline Coumarins & Anti-cancer $^{35}$ \\
\hline Quinones & Antimicrobial $^{36}$ \\
\hline Anthocyanins & $\begin{array}{l}\text { Anti-inflammatory, anti- } \\
\text { microbial, anti-diabetic, anti- }^{30} \\
\text { cancer and anti-obeity }^{37,38}\end{array}$ \\
\hline Terpenoids & Anti-inflammatory $^{39}$ \\
\hline Steroids & Anti-diarrhoeal \\
\hline
\end{tabular}

\section{CONCLUSION}

Plants are important in discovery of new therapeutic compounds. Extraction process serves an important role in identifying lead compound by isolating active compounds from the plant source. There are conventional and non-conventional techniques for extraction of active compounds. Thus, we need to select the suitable extraction procedure depending on the availability. The technique selected for extraction should requires less quantity of solvent and minimum time consuming. The importance to be given for suitable solvent selection also as the efficiency and success rate depends on suitable solvent. There are many solvents like ethanol, methanol, ether but the most ideal properties of solvent are that it should be less toxic should available at low price and it should be harmless and easily evaporated. Thus, by selecting appropriate technique of extraction and suitable solvent the overall efficiency will be improved. Modern extraction procedures like ultrasound assisted extraction, microwave assisted extraction have many advantages over conventional techniques and thus makes easier to identify the lead compound with minimum time. Thus, extraction process plays an important role in drug discovery by identifying the lead compounds.

Funding: No funding sources

Conflict of interest: None declared

Ethical approval: Not required

\section{REFERENCES}

1. Oancea S, Grosu C, Coman D, Stoia M. Conventional and non-conventional extraction of anthocyanins from Rubus idaeus $\mathrm{L}$ grown in Romania. Advances in Environmental technologies, Agriculture, Food and Animal Sciences; 2013: 247251.

2. Selvamuthukumaran M, Shi J. Recent advances in extraction of antioxidants from plant by-products processing industries. Food Quality Safety. 2017;1(1):61-81.

3. Kothari V, Gupta A, Naraniwal M. Comparative study of various methods for extraction of antioxidant and antibacterial compounds from plant seeds. $\mathbf{J}$ Natural Remedies. 2012;12(2):162-73.

4. Azwanida NN. A review on the extraction methods use in medicinal plants, principle, strength and limitation. Med Aroma Plants. 2015;4:2-6.

5. Tartian AC, Cotea VV, Niculaua M, Zamfir CL, Colibaba CL, Morasanu AM. The influence of different techniques of maceration on the aromatic and phenolic profile of the aromatic and phenolic profile of the Busuioaca de Bohotin wine. Bio web Conferences; 2017: 9.

6. Rivero FJ. Impact of post fermentative maceration with overripe seeds on the color stability of red wines. Food Chem. 2019;272:329-36.

7. Zhang $\mathrm{QW}$, Lin LG, Ye WC. Techniques for extraction and isolation of natural products: a comprehensive review. Chinese Med. 2018;13:20.

8. Fuleky G, Czinkota I. Hot water percolation (HWP): A new rapid soil extraction method. Plant Soil. 1993;157:131-5.

9. Kalia VC, Lal S, Rashmi. Modified cold percolation method for extracting oil from oil seeds. J Scientific Industrial Res. 2002;61(8):630-4.

10. Cowan MM. Plant products as anti-microbial agents. Clinical Microbiology Reviews. 1999;12(4):564-82.

11. Adouni K, Mekhelfi T, Daouadji MZD, Achour L. Decoction, Infusion and ethanolic extract of Juncus acutus Rhizome: Phytochemical content and Antioxidant properties. Int $\mathrm{J}$ Pharm Sci Res. 2018;48(1):148-52.

12. Singh J. Maceration, percolation and infusion techniques for the extraction of medicinal and aromatic plants. Extraction technologies for medicinal and aromatic plants; International centre for science and high technology, Trieste, Italy; 2008.

13. Nagalingam A. Drug delivery aspects of Herbal medicines. Japanese Kampo Medicines for the 
treatment of common diseases. Focus on Inflammation; 2017: 143-64.

14. Komarek M, Chrastny V, Ettler V, Tlustos P. Evaluation of extraction/digestion techniques used to determine lead isotopic composition in forest soils. Analytical Bioanalytical Chemistry. 2006;385(6):1109-15.

15. Castro MDL, Ayuextso GLE. Soxhlet extraction of solid materials: an outdated technique with a promising innovative future. Analytical Chimica Acta. 1998;369(1-2):1-10.

16. Redfern J, Kinninmonth M, Verran J. Using Soxhlet Ethanol Extraction to produce and test plant material (Essential Oils) for their antimicrobial properties. J Microbial Biol Educ. 2014;15(1):45-6.

17. Delazar A, Nahar L, Hamedeyszdan S, Sarker SD. Microwave assisted extraction in natural products isolation. Methods Mol Biol. 2012;864:89-115.

18. Tatke P, Jaiswal Y. An overview of Microwave assisted extraction and its applications in herbal drug research. Res J Med Plants. 2011;5(1):21-31.

19. Gupta A, Naraniwal M, Kothari V. Modern extraction methods for preparation of bioactive plant extracts. Int J Applied Natural Sci. 2012;1(1):8-19.

20. Altemimi A, Watson DG, Choudhary R, Dasari MR, Lightfoot DA. Ultrasound assisted extraction of phenolic compounds from peaches and pumpkins. PLOS ONE. 2016;11(2).

21. Torres NM, Ayora T, Andrews HE, Sanchez A. Ultrasound assisted extraction for the recovery of phenolic compounds from vegetable sources. Agronomy. 2017;7:1-19.

22. Esclapez MD, Garcia PJV, Mulet A, Carcel JA. Ultrasound extraction of natural products. Food Eng Rev. 2011;3(2).

23. Sapkale GN, Patil SM, Surwase US, Bhatbhage PK. Supercritical fluid extraction: a review. Int J Chem Sci. 2010;8:729-43.

24. Bhusnure OG. Importance of supercritical fluid extraction techniques in pharmaceutical industry: a review. Indo-American $\mathrm{J}$ Pharmaceutical Res. 2015;5(12):3785-99.

25. Wrona O, Rafinska K, Mozenski C, Buszewski B. Supercritical fluid extraction of bioactive compounds from plant materials. J AOAC Int. 2017;100(6):162435.

26. Ayre A. Supercritical fluid extraction: a green paradigm in the area of separation science. Asian $\mathbf{J}$ Biomedical Pharmaceutical Sci. 2013;3(23):1-7.

27. Das K, Tiawari RKS, Shrivastava DK. Techniques for evaluation of medicinal plant products as antimicrobial agent: Current methods and future trends. J Med Plants Res. 2010;4(2):104-11.
28. Wng GX. In vivo anti-helmintic activity of five alkaloids from Macleaya microcarpa (Maxim) Fedde against Dactylogyrusintermedius in Carrasius auratus. Veterinary Parasitol. 2010;171:305-13.

29. Ncube NS, Afolayan AJ, Okoh AI. Assessment techniques of antimicrobial properties of natural compounds of plant origin: current methods and future trends. African J Biotechnol. 2008;7(12):1797806.

30. Hussain G. Role of plant derived alkaloids and their mechanism in Neurodegenerative disorders. Int J Biol Sci. 2018;14(3):341-57.

31. Evans RC, Miller N, Paganga G. Anti-oxidant properties of phenolic compounds. Trends in plant Science. 1997;2(4):152-9.

32. Panche NA, Diwan DA, Chandra RS. Flavanoids: an overview. J Nutritional Sci. 2016;5(47):1-15.

33. Man S, Gao W, Zahang Y, Huang L, Liu C. chemical study and medical application of saponins as anticancer agents. Fitoterapia. 2018;81(7):703-14.

34. Ashok KP, Upadhyaya K. Tannins are Astringent. J Pharmacognosy Phytochemistry. 2012:1(3):45-50.

35. Rohini K, Srikumar PS. Theraapeutic role of Coumarins and Coumarin related compunds. J Thermodyn Catal. 2014;5(2):1-3.

36. Cowan MM. Plant products as anti-microbial agents. Clinical Microbiology Reviews. 1999;12(4):564-82.

37. He K, Li X, Chen X. Evaluation of antidiabetic potential of selected traditional Chinese medicines in STZ induced diabetic mice. J Ethnopharmacol. 2011;137(3):1135-42.

38. Pojer E, Mattivi F, Johnson D, Stockley CS. The case for anthocyanin consumption to promote human health: a review. Compr Rev Food Sci Food Safety. 2013;12:483-508.

39. Gallily R, Yekhtin Z, Hanus OL. The antiinflammatory properties of Terpenoids from Cannabis. Cannabis Cannabinoid Res. 2018;3(1):282-90.

40. Maniyar Y, Bhixavatimath P, Agashikar NV. Antidiarrheal activity of flowers of Ixora Coccinea Linn in rats. J Ayurveda Integr Med. 2010;1:287-91.

Cite this article as: Saravanabavan N, Salwe KJ, Codi RS, Kumarappan M. Herbal extraction procedures: need of the hour. Int J Basic Clin Pharmacol 2020;9:1135-9. 